\title{
Demographic Factors Determining Compliance to Iron Supplementation in Pregnancy in Oyo State, Nigeria
}

\author{
"M.D. Dairo MBBS, FWACP, "T.O. Lawoyin MBBS, FWACP \\ Department of *Community Medicine, College of Health Sciences, Ladoke Akintola University of Technology, \\ Osogbo Campus, Osun State, ${ }^{*}$ Community Medicine, University College Hospital, Ibadan, Nigeria
}

\begin{abstract}
Background: Iron deficiency anaemia in pregnancy has irreversible negative consequence on infant cognitive development and increases maternal morbidity and mortality. Iron supplementation ameliorates this effect. The salutary effect of iron supplementation on improvement of haemoglobin levels in pregnancy has been documented in various studies. However factors affecting the compliance of women with prescribed iron supplements are yet to be well studied, particularly at primary care levels. This study describes the compliance rate and demographic factors influencing use of iron supplements among pregnant women at primary care level.

Method: This is a cross sectional descriptive study. Five hundred and ninety seven women attending randomly selected primary care centres were studied. Demographic characteristics and information on use of iron supplements were collected. Haemoglobin level was also determined for each woman.
\end{abstract}

Results: Compliance rate was $37.5 \%$. Prevalence of anaemia was higher among noncompliant women than those complying (18\% v 15\%, $\left.X^{2} 7.5, p=0.006\right)$. Haemoglobin level was higher among women complying with iron supplements compared with those not complying (11.4g/dl v 11.0g/dl, $t=9.3, p=0.002)$. Single and teenage mothers and those aged 35years and above were less likely to be compliant. Married women, those in urban location, and those aged 20-29 years were more compliant with iron supplementation.

Conclusions: Pregnancy among teenage and single mothers is associated with a significantly higher risk of non-compliance with iron supplementation. Further studies are recommended to understand the reasons for non-compliance among these groups of women.

KEYWORDS: Anaemia in Pregnancy; Iron Supplementation; Compliance.

Paper accepted for publication 3rd April 2006.

\section{INTRODUCTION}

Approximately $20 \%$ of women in industrialized countries suffer from iron deficiency while approximately $58 \%$ of pregnant women are so afflicted in the developing countries ${ }^{1}$. Iron deficiency in pregnancy usually results from deficient iron stores in the pre-pregnancy state. The iron requirement of a non pregnant woman to replenish the loss through normal menstruation has been calculated to be about $25 \mathrm{mg}$ per month, to which must be added the normal skin loss of $15 \mathrm{mg}$ per month ${ }^{2}$. Thus, in the pre-pregnancy state, a total of $40 \mathrm{mg}$ of iron is lost monthly. Dietary sources of absorbed iron therefore must be greater than $40 \mathrm{mg}$ monthly to achieve a positive iron balance in the prepregnancy state. During pregnancy, the cessation of menstrual flow conserves an approximate $800 \mathrm{mg}$ of iron throughout pregnancy. However fetal growth requirements and deposition of iron in the fetal bone and placenta requires approximately $1800 \mathrm{mg}$ of iron. Thus, a net of $1000 \mathrm{mg}$ of elemental iron is required to maintain iron balance in pregnancy ${ }^{2-3}$ Tropical diet are deficient in iron ${ }^{2}$, predisposing the pregnant woman to negative iron balance and risk of iron deficiency anaemia. Therefore iron supplementation is necessary to maintain positive iron balance. Routine iron supplementation has been accepted on the strength of evidence as necessary to reduce the risk of iron deficiency anaemia in pregnancy ${ }^{4}$ 5

Compliance with iron supplementation is necessary to prevent iron deficiency anaemia which causes significantly increased maternal mortality and morbidity and possible impairment of foetal cognitive development. Infants of mothers who had iron supplementation in pregnancy have been documented to have increase mean length and apgar scores at birth compared to those not on iron supplementation. Infants of iron deficient mothers have also been documented to be at increased risk of iron deficiency ${ }^{6,16-18}$.

In Nigeria, studies on compliance with iron supplementation have not been well documented. Worldwide, data on compliance rate is biased towards women in tertiary centres and those who participate in clinical trials ${ }^{6-7}$. Thus the reported rates do not represent the actual compliance rates within the community. Primary care centres are the first point of contact with modern health care and data from this level approximates closely to the true level of compliance with iron supplementation in the community. 
This study was therefore carried out to determine compliance with iron supplementation and identify the women at high risk of noncompliance at the primary care level.

\section{PATIENTS AND METHODS}

This is a cross sectional descriptive study of pregnant women attending the primary health care clinics of selected urban and rural local government areas (LGAs) in Oyo state, in southwestern Nigeria. There are 33 LGAs in the state. These were stratified into urban and rural LGAs based on Smelser's criteria'. One rural and two urban LGAs were chosen by simple random sampling procedure from a sampling frame of the LGAs. The selected LGAs were the Ibarapa central (rural) and Ibadan Northwest and Ibadan North LGAs (urban). All primary care centres providing antenatal and delivery services in these LGAs were chosen for the study. All pregnant women attending the booking clinics of these centres between February and July 2002 were interviewed using a structured questionnaire. Information on demographic and obstetrics characteristics of the women and their use of prescribed iron preparation in this pregnancy were obtained. Blood was drawn from the antecubital vein into potassium EDTA bottles and haemoglobin determined by the Sahli's method of haemoglobin estimation'.

Compliance was defined as the use of $300 \mathrm{mg}$ ferrous sulphate or $200 \mathrm{mg}$ ferrous fumarate orally three times daily, prescribed by the health worker attending to the women at booking. The iron tablets were supplied free by the state government under its free health policy. This ensures availability and affordability of the drug during the study. Compliance was monitored by asking for report of change in the colour of the stool to blackish. Women who use any other form of iron preparation were excluded from the study. Anaemia was defined as haemoglobin less than $11 \mathrm{~g} / \mathrm{dl}^{10}$. Location of the health centre was classified as urban or rural based on the Smelser's criteria. Age was measured as at last birthday. Socioeconomic status was based on the British Registrar General's classification of occupational groups ${ }^{11}$. The socioeconomic status was reclassified into high, middle and low socioeconomic status. Those in occupational groups I and II in the British Registrar General's classification were classified as high socioeconomic class. Occupational group III was classified as middle socioeconomic class while those in groups IV and V were classified as low socioeconomic class.

Data was entered into the EPI Info v6 software. Variables were categorized where possible before comparison was done. Association between demographic and obstetric variables and use of iron supplements was determined by Chi square test. Mean of quantitative variables were compared with the student's $t$ test. Level of significance was set at $95 \%$ confidence interval.

\section{RESULTS}

Five hundred and ninety seven women participated in the study. Two hundred and twenty four (37.5\%) of the women were using some form of iron preparation in the index pregnancy. Compliance with iron supplementation (37.5\%) was thus very poor among the women.

Demographic and obstetric characteristics of the women are shown in the Table I. Among those anaemic, proportion of those on iron supplementation is significantly less than those who are not on iron supplementation. This association is statistically significant $\left(X^{2} 7.5=p<0.006\right)$. Mean haemoglobin among compliant women was statistically significantly higher than among non-compliant women $(11.4 \mathrm{~g} / \mathrm{d}$ v11.0g/dl, p <0.002) Table I.

In the urban location, $185(31 \%)$ of the women complied with their iron prescriptions compared to $40(6.7 \%)$ in the rural area $\left(X^{2}=41.59 p<0001\right)$. This difference was statistically significant Table II.

Teenagers and women older than 35years of age also have statistically significantly lower compliance compared to those aged $20-24$ and 2529 years $\left(X^{2}=\right.$ $14.71 p<0.005)$. Women in the lower socio-economic status also have a significantly better compliance than those in the higher and middle socio-economic status $\left(X^{2}=7.74, p<0.02\right)$. Married women are also more likely to use iron supplements compared to the unmarried (single and separated) $\left(X^{2}=10.48 p<0.005\right)$. Women with no formal education and those with tertiary education seemed to comply poorly with iron supplementation in contrast to those with primary education although this is not statistically significant.

Compliance with iron supplementation is higher in women with low parity. Use of iron supplement is particularly high within parity groups one and two and lowest in the grand multipara. Compliance is highest in women who book in the second trimester compare to others although this is not statistically significant.

Table I. Prevalence of Anaemia and Compliance with Iron Supplementation

\begin{tabular}{lcccc}
\hline & \multicolumn{4}{c}{ Iron supplement \{No (\%)\} } \\
Characteristic & Total & Yes & No & P \\
& & & & \\
\hline Anaemia & $196(32.9)$ & $89(45.4)$ & $107(54.6)$ & 0.006 \\
Mean Haemoglobin & $11.1 ? 1.1$ & $11.4 ? 0.9$ & $11.0 ? 1.0$ & 0.002 \\
\hline
\end{tabular}


Table II. Demographic Factors and Compliance with Iron Supplementation

\begin{tabular}{|c|c|c|c|c|}
\hline \multirow[b]{2}{*}{ Characteristic } & \multicolumn{3}{|c|}{$\begin{array}{c}\text { Iron supplement } \\
\text { No }(\%)\end{array}$} & \multirow{2}{*}{$P$} \\
\hline & \multirow[t]{2}{*}{ Total } & \multirow[t]{2}{*}{ Yes } & No & \\
\hline Location & & & & \\
\hline Urban & 395(66.2) & 185(31) & $210(35.2)$ & 0.0001 \\
\hline Rural & $202(33.8)$ & $40(6.7)$ & $162(27.1)$ & \\
\hline Age (in years) & & & & \\
\hline$<19$ & 63(10.6) & $12(2.0)$ & $51(8.6)$ & \\
\hline $20-24$ & $208(35.1)$ & $84(14.2)$ & $124(20.9)$ & 0.005 \\
\hline $24-29$ & $169(28.5)$ & $74(12.5)$ & $95(16)$ & \\
\hline $30-34$ & $108(18.2)$ & $42(7.1)$ & $66(11.1)$ & \\
\hline $\begin{array}{l}? 35 \\
\text { Marital status }\end{array}$ & $44(7.4)$ & $12(2.0)$ & $32(5.3)$ & \\
\hline Single & $56(9.4)$ & $14(2.3)$ & $42(7.0)$ & 0.05 \\
\hline Married & $537(89.9)$ & $209(35)$ & $22.8(54.9)$ & \\
\hline Separated & $4(0.7)$ & $2(0.3)$ & $2(0.3)$ & \\
\hline $\begin{array}{l}\text { Education } \\
\text { Nil formal }\end{array}$ & $42(7.0)$ & $15(25)$ & $27(45)$ & \\
\hline $\begin{array}{l}\text { Nil formal } \\
\text { Primary }\end{array}$ & $\begin{array}{c}42(1.0) \\
256(42.9)\end{array}$ & $91(15.2)$ & $165(27.6)$ & 0.76 \\
\hline Secondary & $267(44.7)$ & $106(17.8)$ & $161(27)$ & \\
\hline Tertiary & $32(5.4)$ & $13(2.2)$ & $19(3.2)$ & \\
\hline $\begin{array}{l}\text { Socioeconomi } \\
\text { c Status }\end{array}$ & & & & \\
\hline Higher & $58(9.7)$ & $13(2.2)$ & $45(7.5)$ & 0.02 \\
\hline Middle & $35(5.9)$ & $17(2.9)$ & $18(3.0)$ & \\
\hline Lower & $504(84.4)$ & $195(32.7)$ & $309(51.8)$ & \\
\hline Parity & & & & \\
\hline 0 & $178(24.8)$ & 59(9.9) & 119(19.9) & \\
\hline 1 & $156(26.1)$ & $61(10.2)$ & $95(15.9)$ & \\
\hline 2 & $125(20.9)$ & $57(9.5)$ & $68(11.4)$ & 0.19 \\
\hline 3 & $90(15.1)$ & $33(5.5)$ & $57(9.5)$ & \\
\hline 4 & $32(5.4)$ & $11(1.8)$ & $21(3.5)$ & \\
\hline$? 5$ & $16(2.7)$ & $4(0.7)$ & $12(2.0)$ & \\
\hline $\begin{array}{l}\text { Trimester at } \\
\text { booking }\end{array}$ & 4(0.7) & $2(0.3)$ & $2(0.3)$ & \\
\hline First & $456(76.4)$ & $175(29.3)$ & $281(47.1)$ & 0.68 \\
\hline $\begin{array}{l}\text { Second } \\
\text { Third }\end{array}$ & $137(22.9)$ & $48(8.0)$ & $89(14.9)$ & \\
\hline
\end{tabular}

\section{DISCUSSION}

The compliance rate found in this study was $37.5 \%$, a rate similar to that obtainable in developed countries such as Sweden in which iron deficiency anaemia is low among the pregnant women. Nordeng $\mathrm{H}$ et al in a study of 431 parous Scandinavian women found a compliance rate of $27 \%{ }^{12}$. In another study of pregnant women in Sweden, a compliance rate of $28 \%$ was observed among women attending the antenatal clinics $^{13}$, however the compliance rate is low compared to other developing countries in which iron deficiency anaemia is prevalent in pregnancy, for example, Indonesia in Southeast Asia. In Indonesia, a higher compliance rate of $64 \%$ was found ${ }^{14}$. This compliance was confirmed with positive serum ferritin.

The compliance rate in this study is also low compared to the national target as contained in the strategies for the implementation of the National reproductive agenda in Nigeria ${ }^{15}$.

Higher compliance was also observed among women in the lower socioeconomic class compared to the upper socioeconomic class. This is could have resulted from the differential patronage of primary health care centres by the different socioeconomic classes. In many developing countries the primary care level is bypassed by the upper and middle socioeconomic classes because they consider the quality of care offered by this level as low. Therefore the higher compliance among the lower socioeconomic class could be ascribed to higher patronage by its members who cannot afford higher levels of care which they consider as too expensive.

During the period of the study the iron tablets were supplied free by the state health authorities under her free health programme thus financial access does play a significant role in determination of the compliance. Although the study did not attempt to clarify the reasons for the differential compliance, disparity in health resources and utilization of health care was suggested based on the higher compliance among urban women compared with rural women.

Pregnancy among teenagers had been shown by other authors to be associated with many risks and poor pregnancy outcome. Anaemia is one of the risks so identified. The observation of low compliance with iron supplementation among the teenagers indicates a greater risk demanding action to reduce the potential infant morbidity and maternal morbidity and mortality that may result from iron deficiency anaemia ${ }^{14,17}$.

The observation of higher compliance among women who book in the second trimester compared to the third trimester reveals that encouragement of early booking will enhance compliance among the women. Early booking gives more opportunity to attend antenatal clinics where health talks are given regularly. This has a potential of increasing compliance through the constant reminders given during the health talks.

In conclusion, compliance with iron supplementation is generally low among women in our community. The women at higher risk of poor compliance with iron supplementation are single and teenage mothers. Efforts should be directed at these particularly vulnerable groups to prevent possible and avoidable maternal morbidity and mortality and also infantmorbidity.

\section{REFERENCES}

1. WHO. The Prevalence of anaemia in women: A Tabulation of Available Information. Second Edition, Maternal Health and Safe Motherhood Program (Nutrition Program). Geneva, Switzerland 1992.

2. Lawson JB: Anaemia in pregnancy. In: Lawson JB, Stewart DB (eds). Obstetrics and Gynecology in the Tropics and Developing Countries. First Edition. London . Edward Arnold (Publisher) Limited; 1983:73-99.

3. Whitfield CR. Blood Disorders in Pregnancy.In: Dewhurst's Textbook of Obstetrics and Gynaecology. Fifth Edition. London Blackwell Science Limited 1995: 228-250.

4. Beaufrere $B$, Bresson $\mathrm{JL}$, Briend $\mathrm{A}$, et al. Iron and pregnancy. Arch Paediatr 1995; 2 (12): 1209-18.

5. Buytert G, Wallenburg HC, van Eijek HG, Buytert P. Iron supplementation during pregnancy. Eur $\mathrm{J}$ Obstet 
Gynecol Reprod Biol 1983; 15(1): 11-16.

6. Kilbride J, Baker TG, Parapia LA, Khoury SA, Shaqaidef SW, Jerword D. Anaemia as a risk factor for iron deficiency anaemia in infancy: a case control study in Jordan. Int J Epidermiol 1999; 28 (3): 461- 8.

7. Young MW, Lupafya E, Kepandu E, Bobrow E.A. The effectiveness of weekly iron supplementation in pregnant women of rural Northern Malawi. Tropical Doctor 2000; 30 (2): 848.

8. Smelser A (Ed): Sociology An Introduction. Second Edition.New York. John Wiley, 1973:23.

9. Cheesbrough M. District Laboratory Practice in Tropical Countries Part 2. Cambridge University Press Low Price Edition. Cambridge. 2002; 307.

10. World Health Organization. Nutritional Anaemias. World Health Organization Tech Rep Ser 1972:503.

11. Registrar General's Mortality Statistics (1975) Series DH 3No 2. HMSO. London 1975.

12. Nordeng $H$, Esklid A, Nesheim BI. Guidelines for iron supplementation in pregnancy: compliance among 431 parous Scandinavian women. Eur J Clin. Pharmacol 2003; 59 (2): 163 - 8 .
13. Wulff M, Ekstrom EC. Iron supplementation during pregnancy in Sweden: to what extent is the national recommendation followed? Acta obstetric Gynaecol Scand. 2003; 82(7):628 - 35.

14. Schultink W, van der Ree M, Matulessi P, Gross R. Low compliance with iron supplementation program: a study among pregnant women in Jakarta, Indonesia. Am J Clin Nutr 1993; 57(2): $135-9$.

15. Federal Republic of Nigeria. National Reproductive Health Policy \& Strategy to Achieve Quality Reproductive \& Sexual Health for All Nigerians. Federal Ministry of Health Abuja, Nigeria. 2001:22.

16. Preziosi $P$, Prual $A$, Galan $P$, et al. Effect of iron supplementation on the iron status of pregnant women: consequences for newborns. Am J Clin Nutr 1997 66(5): 1178-82.

17. Wagener IE, Bergmann RL, Kamtsiuris $P$, et al. Prevalence and risk factors of iron deficiency in young mothers Gesundheitswesen $2000 ; 62$ (3): 176-8.

18. Allen $H$. Pregnancy and iron deficiency: unresolved issues. Nutr Rev 1997; 55(4):91-101. 